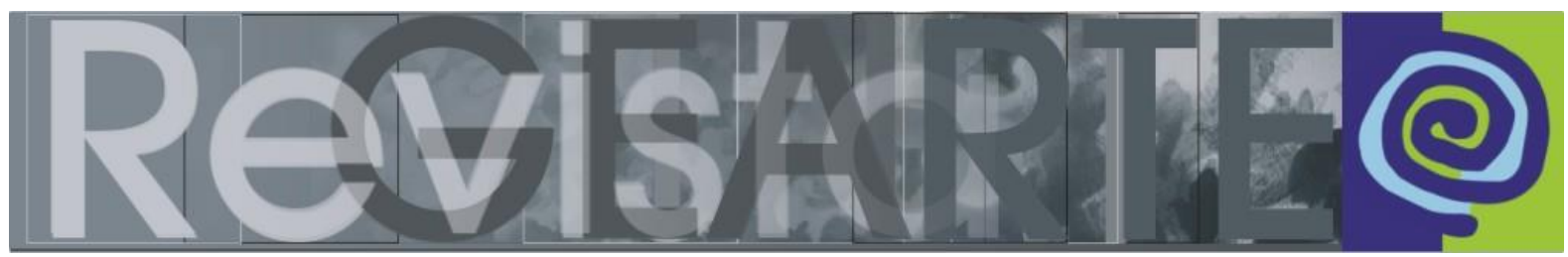

ISSN 2357-9854 | e-ISSN 2596-3198 (online)

\title{
Formação colaborativa: uma possibilidade de habitar o Museu de Arte com a Pequena Infância ${ }^{1}$
}

\author{
Solange Gabre \\ (Secretaria Municipal da Educação de Curitiba - SME, Curitiba/PR, Brasil)
}

\begin{abstract}
RESUMO - Formação colaborativa: uma possibilidade de habitar o Museu de Arte com a Pequena Infância - Este texto aborda a prática da formação continuada tendo o trabalho colaborativo como uma possibilidade para que crianças pequenas, aquelas entre quatro e cinco anos de idade inseridas no contexto da educação infantil, tenham seu direito de acesso a arte e cultura efetivado na prática. As reflexões partem de um recorte da investigação "Para Habitar o Museu com o Público Infantil: uma proposta de formação colaborativa entre professoras da infância e profissionais do Museu Municipal de Arte de Curitiba"2. Os pressupostos teóricos envolveram estudos sobre educação museal (Mörsch, Huerta); educação Infantil e educação infantil no museu os trabalhos (Leite); formação continuada, formação cultural e trabalho colaborativo (Nóvoa, Kramer, Leite e Ostetto, Arslan e lavelberg, Nogueira, Carvalho, Martins, Day, Imbernón, Rodrigo, Eça, Arriaga e Coca). As conclusões indicam que a formação cultural inserida no processo de formação continuada, como formação colaborativa, é uma possibilidade de contribuir no desenvolvimento profissional de professores da infância e de profissionais do museu, necessário para que as crianças pequenas possam habitar o museu de arte.
\end{abstract}

PALAVRAS-CHAVE

Educação. Formação colaborativa. Criança. Museu. Arte.

RESUMEN - Formación colaborativa: una posibilidad de habitar el Museo de Arte con la Pequeña Infancia - Este texto se refiere a la práctica de la formación continuada teniendo el trabajo colaborativo como una posibilidad para que los niños pequeños, aquellos entre cuatro y cinco años insertados en el contexto de la educación infantil, tengan su derecho de acceso al arte y la cultura efectiva en la práctica. Las reflexiones parten de un recorte de la investigación "Para Habitar el Museo con el Público Infantil: una propuesta de formación colaborativa entre profesoras de la infancia y profesionales del Museo Municipal de Arte de Curitiba". Los presupuestos teóricos adoptados involucraron los estudios sobre educación museal (Mörsch, Huerta); de la educación infantil y la educación infantil en el museo, los trabajos (Leite); formación continua, formación cultural y trabajo colaborativo (Nóvoa, Kramer, Leite y Ostetto Arslan e lavelberg, Nogueira, Carvalho, Martins, Day, Imbernón, Rodrigo, Eça, Arriaga y Coca). Las conclusiones indican que la formación cultural insertada en el proceso de formación continuada, como formación colaborativa, es una posibilidad de contribuir en el desarrollo profesional de profesores de la niñez y de profesionales del museo, necesario para que los niños pequeños puedan habitar el museo de arte.

PALABRAS CLAVE

Educación. Formación colaborativa. Niño. Museo. Arte.

1 A pequena infância, segundo Plaisance (2004), compreende as crianças em idade que precedem a escolarização obrigatória, ou seja, aquelas do contexto da educação infantil com faixa etária entre 0 e 5 anos de idade.

2 Defendida no ano de 2016 na Universidade Federal do Rio Grande do Sul, sob a orientação da profa. Dra. Analice Dutra Pillar, a referida pesquisa contou com o apoio do Programa de Doutorado Sanduíche no Exterior (PDSE), oferecido pela Coordenação de Aperfeiçoamento de Pessoal de Nível Superior (CAPES). O estágio se deu na Universidade Complutense de Madrid sob a coorientação da Prof.a . Dra. Maria Acaso Lopez Bosch. Processo n.․ 99999.005195/2014-04.

GABRE, Solange. Formação colaborativa: uma possibilidade de habitar o Museu de Arte com a Pequena Infância. 514

Revista GEARTE, Porto Alegre, v. 6, n. 3, p. 514-527, set./dez. 2019.

http://dx.doi.org/10.22456/2357-9854.92974 


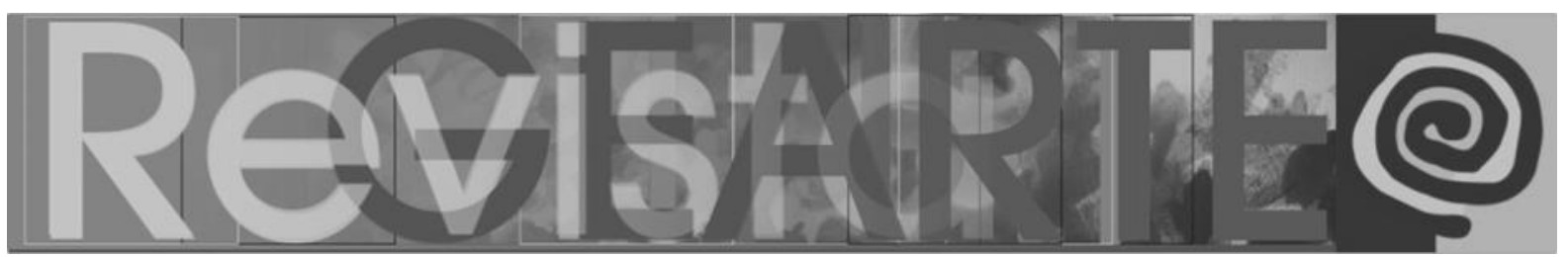

Ao abordar a temática da formação continuada e a atuação profissional na e com a infância, é importante destacá-la como algo bastante recente no contexto brasileiro. Contudo, são notórios os avanços na busca por uma educação de qualidade à primeira etapa da educação básica, principalmente quando o entendimento do conceito de criança como um sujeito histórico e social que possui uma cultura própria e que também é produtora de cultura passa a ser considerado. Esse aspecto, indiscutivelmente, reconfigura a prática docente no contexto da educação escolar e ganha assim outros espaços de atuação social, o museu de Arte, por exemplo, evidenciando a necessidade de inserir a dimensão artístico-cultural na formação dos profissionais que nela atuam.

Sendo assim, a reflexão que se pretende caminha no sentido de fundamentar uma das possibilidades de efetivar o acesso à Arte às crianças pequenas, que considere as especificidades desse público num trabalho colaborativo.

\section{Formação Continuada e a Dimensão Artístico-Cultural no contexto da Educação Infantil}

A formação continuada e a sua dimensão artístico-cultural apresenta-se como um terreno bastante fértil, apesar de pouco valorizada pelas políticas públicas nacionais e explorada em pesquisas acadêmicas. Muitas ações desenvolvidas em diferentes contextos e autores como Kramer (1998, 2000, 2008), Leite e Ostetto (2005), Arslan e lavelberg (2006) lavelberg (2016), Nogueira (2002, 2008), Carvalho (2005, 2007), Leite (2012), Martins (2013), entre outros, têm defendido essa causa e, portanto, nos apoiam nessa reflexão.

A dimensão artístico-cultural, inserida no campo da formação cultural está diretamente relacionada à possibilidade de contato com a arte e a vivência de experiências sensíveis, no contexto formativo, como um dos importantes componentes para o desenvolvimento profissional docente.

Formação cultural abrangendo: 


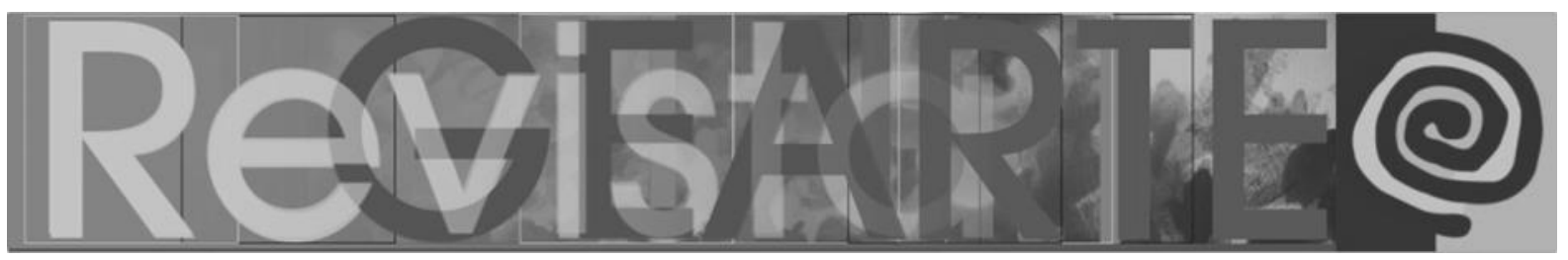

[...] toda e qualquer possibilidade de apropriação nas diferentes esferas da cultura: arte, literatura, folclore, arquitetura, artesanato, dentre tantos outros aspectos e dimensões. Traduz-se pela possibilidade de construção de conhecimentos no âmbito artístico-cultural, os de dimensão estética e poética, ligados a Arte [...]. (LEITE, 2008, p. 57-58)

Em outras palavras, a formação cultural "[...] como o processo em que o indivíduo se conecta com o mundo da cultura, mundo esse entendido como um espaço de diferentes leituras e interpretações do real, concretizado nas artes [...]" (NOGUEIRA, 2008, p. 4), e como um direito de todos. Portanto, cremos na sua importância nos processos de formação continuada como condição de apropriação e de acesso a esse universo, bem como de construção de sentidos e conhecimentos significativos em contextos educativos diversos, uma vez que essa dimensão é bastante escassa nos cursos de formação inicial de professores.

Mesmo a Arte tendo sido contemplada nas Diretrizes Curriculares Nacionais ${ }^{3}$ para os cursos de Pedagogia desde 2006, o Grupo de Pesquisa Arte na Pedagogia (GPAP), coordenado por Mirian Celeste Martins, evidencia em suas pesquisas ${ }^{4}$ (20122013), difundidas em eventos e publicações, que a presença da Arte nesses cursos é ainda um campo bastante confuso e inexistente em algumas instituições.

Apesar disso, é importante verificar que a Arte é componente curricular obrigatório na educação básica, instituída em forma de $l \mathrm{e}^{5}$, por isso ressaltamos a necessidade de se criar condições favoráveis no que se refere à formação inicial do pedagogo, bem como na formação continuada do profissional em exercício. E ao considerarmos os dados de pesquisas desenvolvidas por Gatti; Barretto (2009) e Silva; Almeida; Ferreira (2011), sobre a formação de professores no país, onde evidenciam que o acesso de professores aos bens culturais é cada vez mais restrito, é que reafirmamos com Gatti e Barretto (2009, p.233) que "os processos de formação

3 Diretrizes curriculares para o Curso de Pedagogia, definidas pela Resolução n.1, de 15 de maio de 2006, do Conselho Nacional de Educação - CNE.

4 "Situação da Arte na Pedagogia: levantamento nacional" e "Situação da Arte na Pedagogia: ampliações e análises".

5 Lei 13.278/2016, que inclui as artes visuais, a dança, a música e o teatro nos currículos dos diversos níveis da educação básica, que envolve a educação infantil, o ensino fundamental e o ensino médio. 


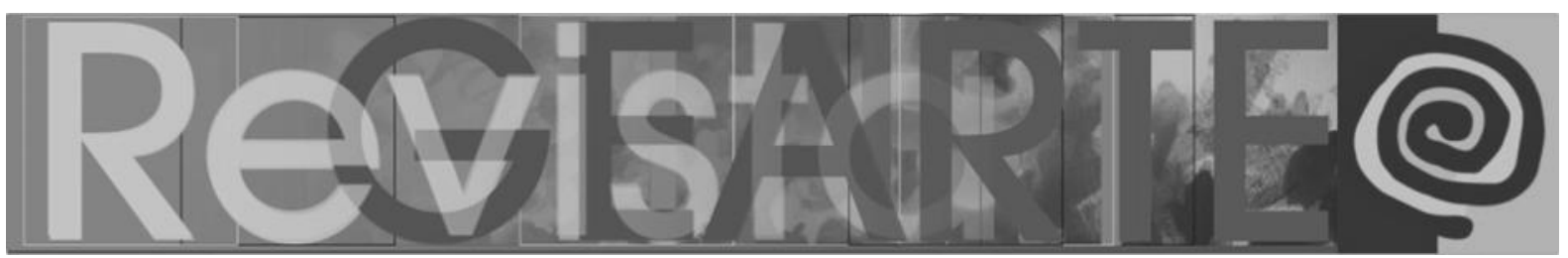

continuada não podem prescindir de estratégias que facilitem o acesso do professor a estes bens.".

Defendemos assim o pressuposto de que:

[...] a experiência de profissionais nos mais diversos espaços culturais pode atuar no sentido de informar seu olhar, sensibilizar e flexibilizar seu conhecimento e, desse modo, propiciar situações que se configurem como importantes momentos de aprendizagem do ponto de vista cultural, ético e estético. Considerando que tal formação constitui os profissionais como pessoas no que se refere ao gosto estético e aos valores éticos, entendendo que ele contribui para a sua atuação no mundo do trabalho, com crianças, jovens e adultos, dentro e fora da escola. (KRAMER, 1998, p. 200)

Neste sentido, Arslan e lavelberg (2006, p. 6) afirmam que "não se pode ensinar aquilo que não se conhece. Para tanto é necessário que o professor entre em contato com vivências, conheça o contexto da produção artística e reflita sobre as obras em seus diversos aspectos". Cabe esclarecer, então, que o recorte aqui elegido dentro do campo da formação cultural é a relação estabelecida com a arte exposta no museu como possibilidade de ampliação de repertório e vivência estética de adultos e crianças em contexto da educação infantil, pois "ampliar repertório de todos é vislumbrar uma sociedade mais respeitosa com as diferenças; é favorecer uma geração mais autônoma, crítica e autoral; é falar de alteridade" (LEITE, 2008, p. 71). Vale, também, justificar que esse recorte se deve ao crescente investimento de professores da educação infantil em momentos de visitas a museus de artes com as crianças pequenas.

Em função disso, é imprescindível questionar de que maneira as políticas públicas investem nesse campo como formação? O profissional da educação infantil tem a possibilidade de visitar museus em momentos de formação continuada? Por outro lado, os museus investem na aproximação com os professores? Existem nos espaços de arte e cultura ações formativas pensadas para/com o professor da educação infantil? Há ações desenvolvidas em parceria entre a escola da infância e o museu? 


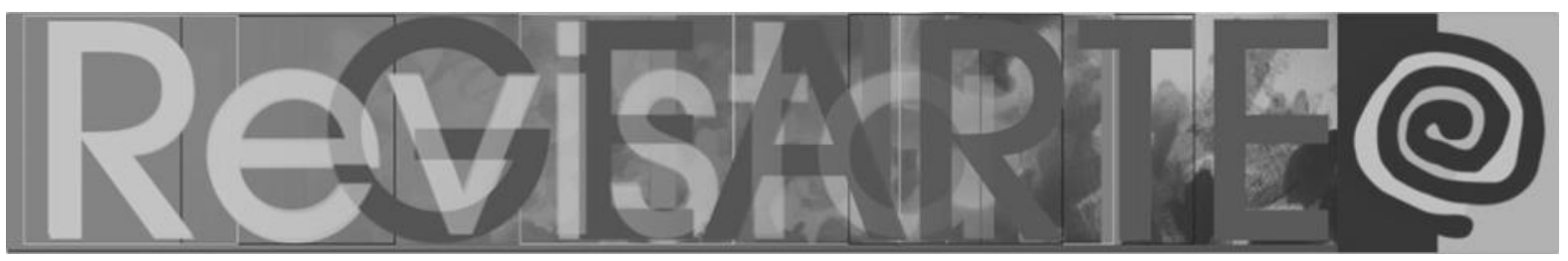

A partir dessas problematizações, a aposta no trabalho colaborativo é uma possibilidade de estreitar relações entre profissionais de modo a garantir às crianças pequenas o acesso de qualidade ao Museu.

\section{O Trabalho Colaborativo no Contexto da Formação Cultural}

A partir dos apontamentos e reflexões realizados até o presente momento, reiteramos a necessidade e importância que assume a formação continuada e a sua dimensão artístico-cultural nos processos formativos dos profissionais da educação infantil. Entretanto, ao abordar essa formação no sentido de pensar ações que envolvam o museu de arte, abrimos a possibilidade de ampliar o olhar para as relações que se estabelecem com os profissionais desse espaço.

Assim, entendemos que a formação cultural deve se abrir para as necessidades reais dos contextos educativos na interface entre educação escolar e educação museal. Neste caso em particular, a escola da infância e o museu de arte num trabalho colaborativo entre os profissionais. Para tanto, é imperativo que os modelos formativos sejam repensados no sentido de romper com modelos tradicionais, aqueles em que se "permanece predominantemente, dentro de um processo de lições ou conferências-modelo, de noções ministradas em cursos, de uma ortodoxia de ver o modo de formar, de cursos padronizados por experts" (IMBERNÓN, 2009, p. 9).

Desses modelos formativos, observamos que as ações de formação cultural que acontecem no espaço do museu de arte, voltadas aos professores, são comumente realizadas como uma via de mão única, em que o museu oferece e o professor e a escola aceitam.

No entanto, vivemos um período que exige mudanças e dentre elas, mudanças no contexto da educação, considerado obsoleto para os tempos atuais. De acordo com Imbernón (2009, p. 15):

[...] embora há algum tempo os contextos já estivessem mudando vertiginosamente, é nesta época que esses contextos que condicionam a formação refletem uma série de forças em conflito: aparece a nova economia, a tecnologia desembarca com grande força na cultura, a globalização se torna 


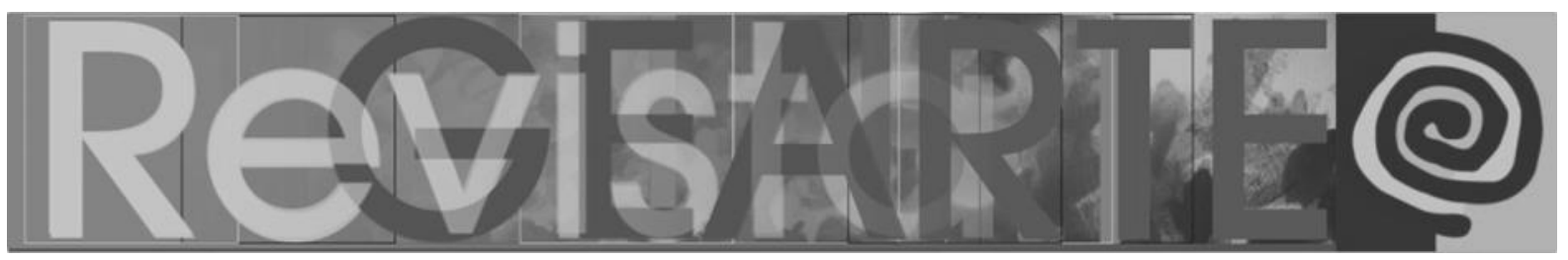

patente [...]. Tem-se a percepção de que os sistemas anteriores não funcionam para educar a população deste novo século, os edifícios não são adequados para uma nova forma de ver a educação, cada vez assume mais importância a formação emocional das pessoas, a relação entre elas, as redes de intercâmbio, a comunidade como elemento importante de educação.

Compreendemos que nesse campo, a formação continuada precisa progredir, pois "avançamos pouco no terreno das ideias e nas práticas políticas para ver o que significa uma formação baseada na liberdade, na cidadania e na democracia" (IMBERNÓN, 2009, p. 15). Por outro lado, avançar significa correr riscos e na maioria das vezes, "[...] as administrações educativas não se atrevem a possibilitar novas alternativas de mudança, já que estas hão de partir de pressupostos diferentes" (IMBERNÓN, 2009, p. 15) daqueles já cristalizados nos sistemas de ensino. É preciso assim, o desejo de um novo olhar para a educação e para a formação, o que pressupõe "[...] a necessidade de estabelecer novos modelos relacionais e participativos na prática da formação. Isso nos conduz a analisar o que aprendemos e o que temos ainda para aprender" (IMBERNÓN, 2009, p. 16).

Essa reflexão nos leva a pensar na possibilidade de a formação cultural contribuir no desenvolvimento profissional, não somente, de professores da infância que desejam integrar o museu nas suas práticas com as crianças pequenas, mas também no desenvolvimento dos profissionais que atuam no museu e que, na grande maioria, carecem de saberes sobre esse público. A questão que se coloca é: de que maneira isso pode ocorrer? Uma possiblidade que vem tomando forma na atualidade é a de se abrir para um trabalho colaborativo. Neste sentido, buscar na formação continuada a colaboração entre educação escolar e educação museal no desenvolvimento de projetos em comum.

O trabalho colaborativo vem sendo fomentado por diferentes autores, tanto do campo da educação quanto no campo da arte educação, dentre eles, Roldão (2007), Nóvoa (2002, 2009), Day (2005), Imbernón (2006, 2009, 2010), Rodrigo (2007), Eça (2009), Huerta (2010), Aguirre (2011), Coca (2014), entre outros. 


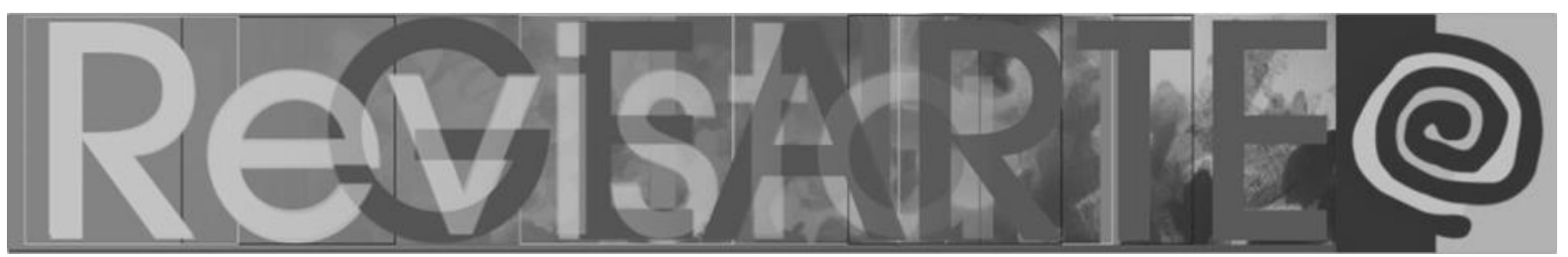

Para Imbernón (2006), o profissional da educação constrói seus conhecimentos pedagógicos de forma individual e coletiva. Partindo desse entendimento, o trabalho colaborativo constitui-se como elemento fundamental para a formação de professores, para a profissionalização docente e para a relação entre o professorado, pois "a colaboração é um processo que pode ajudar a entender a complexidade do trabalho educativo e dar respostas melhores às situações problemáticas da prática" (IMBERNÓN, 2010, p. 65). Conforme o autor:

Quando os professores trabalham juntos, cada um pode aprender com o outro. Isso os leva a compartilhar evidências e informação e a buscar soluções. A partir daqui os problemas importantes das escolas começam a ser enfrentados com a colaboração entre todos, aumentando as expectativas que favorecem os estudantes e permitindo que os professores reflitam sozinhos ou com os colegas sobre os problemas que os afetam (IMBERNÓN, 2006, p. 78).

Nessa mesma ótica, Roldão (2007) reforça que, sendo a aprendizagem um processo contínuo na formação de professores, a reflexão coletiva na análise das situações cotidianas torna-se fundamental. Assim, o trabalho colaborativo:

Estrutura-se essencialmente como um processo de trabalho articulado e pensado em conjunto, que permite alcançar melhor os resultados visados, com base no enriquecimento trazido pela interação dinâmica de vários saberes específicos e de vários processos cognitivos em colaboração (ROLDÃO, 2007, p. 27).

Diante disso, para que o trabalho colaborativo se consolide, é necessário conhecer as finalidades que orientam a ação docente, visando alcançar as aprendizagens pretendidas, ativar as diferentes potencialidades de todos os participantes e "[...] ampliar o conhecimento construído por cada um pela introdução de elementos resultantes da interação com todos os outros" (ROLDÃO, 2007, p. 27).

A partir dessas reflexões, entendemos que o trabalho colaborativo pode romper com as barreiras do contexto formal da educação e avançar para o campo não formal, como já mencionado anteriormente, conectando profissionais de diferentes contextos e instituições com o museu de arte. 


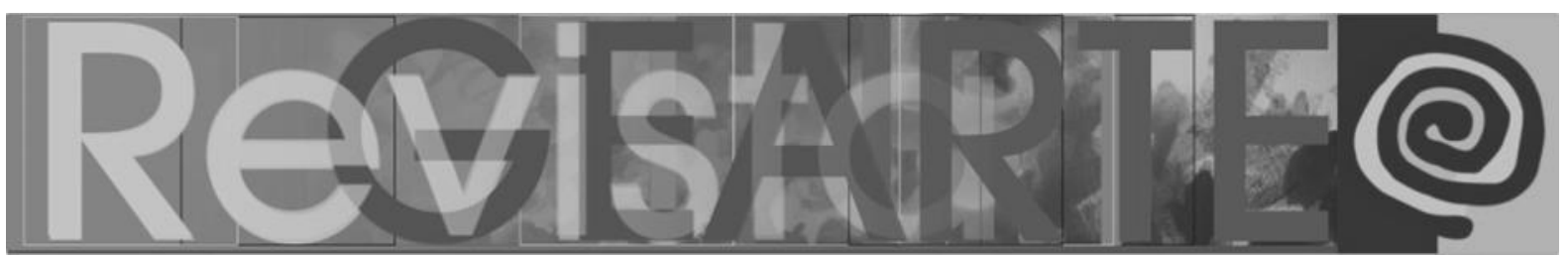

Carmen Mörsch contribui com essa reflexão no sentido de entendermos a colaboração como "una relación entre dos o más entidades, que define los contenidos del trabajo conjunto desde los intereses de ambos colaboradores" (MÖRSCH, 2015, p. 25) o que é evidenciado em seu artigo "Educación en Museos y centros de arte como práctica colaborativa”.

Assim, salientamos que imaginar uma aproximação entre escolas da infância e museus de Arte, a partir de um trabalho colaborativo entre os profissionais de ambos os contextos é um caminho possível na atualidade. No entanto, há a necessidade de esforços e interesse de todos os agentes e instituições implicados nessa ação.

\section{Práticas colaborativas entre escolas e museus: uma possibilidade de construir juntos}

Ao conceber ações dentro de uma perspectiva colaborativa é importante salientar que a relação entre escolas e museus demonstra um duplo direcionamento:

Por un lado, compartir y negociar el curriculum escolar de la formación en artes. Pero hacerlo sin la habitual resistencia que se ofrece desde la escuela, bajo el argumento de que los educadores de museos y los teóricos del arte no conocen suficientemente la realidad escolar. Por otro lado, compartir y negociar el carácter y enfoque de las actividades y programas de formación en artes que ofrecen los museos. Pero hacerlo sin adoptar la demasiado habitual posición paternalista, consistente en no hacer partícipes de la organización y prácticas de los departamientos educativos de estas instituciones a los docentes. En este caso, bajo el argumento de que los conocimientos del profesorado generalista sobre las artes y los museos son limitados. (ARRIAGA, 2011, p. 20)

Esse posicionamento indica que, ao trabalhar em colaboração, cada instituição necessita se abrir para as mudanças e transformações que se fazem necessárias. Não se trata de confundir a educação que acontece no museu com a educação da escola. Alguns autores afirmam que muitas vezes há certa escolarização dos museus, quando práticas que ocorrem na escola, frequentemente são incorporadas em seus espaços. De acordo com Lopes (1991, p. 5):

[...] o papel educacional que cabe aos museus, e há anos vem sendo debatido nos fóruns museológicos internacionais, reflete o fato de que a grande maioria do público que os frequenta é composta de crianças e jovens levados por 


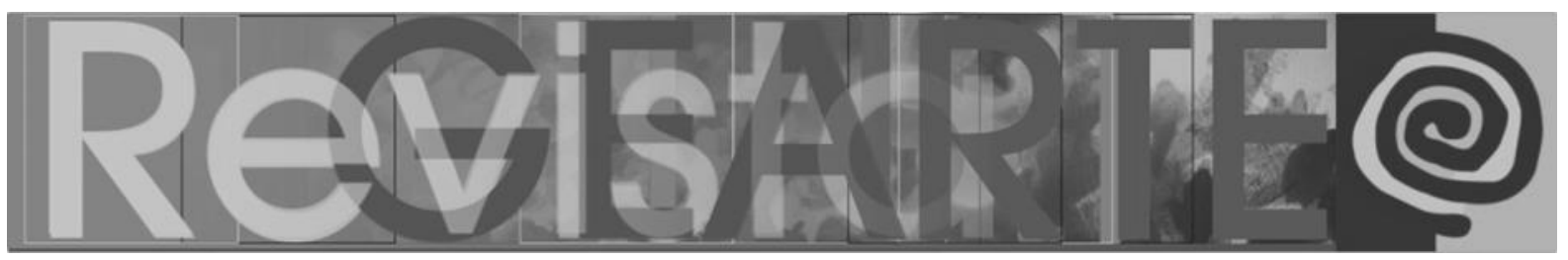

suas escolas, para as tradicionais visitas guiadas, ou outras atividades que em essência vêm significado a transposição para o interior do museu das metodologias e práticas do ensino escolar. Chamamos escolarização a esse processo de incorporação pelos museus das finalidades e métodos do ensino escolar, cujas manifestações Iniciais surgiram com os movimentos escolanovistas e vêm se aprofundando no bojo das propostas de educação permanente para museus.

Neste sentido, Santos (1997, p. 28) reforça que “a 'escolarização' do museu seria um equívoco, visto que este deveria procurar promover atividades baseadas em metodologias próprias" e que acompanhem o pensamento e as transformações do mundo contemporâneo.

Ações que apostam na mudança de práticas cristalizadas devem investir em um trabalho "permanente, dialogado e equilibrado" (ARRIAGA, 2011, p. 20), entre os profissionais de escolas e museus. Nesta mesma linha, Alderoqui (2015, s/p) ressalta a necessidade de uma mudança de paradigma dentro das instituições museológicas e de "estabelecer um sentimento de confiança no potencial dos projetos participativos, que devem ser assumidos por todos os que trabalham no museu." Acrescentamos que isso precisa ocorrer também na escola.

Um exemplo bastante recente sobre a prática colaborativa entre escolas e museus é o projeto "Aquí trabaja un artista" realizado pelo Departamento de Educação do Centro de Arte Dos de Mayo, nas proximidades de Madrid (Espanha), em colaboração com instituições escolares. O projeto foi desenvolvido no período escolar de 2014-2015. Trata-se de uma proposta de residência de dois artistas em escolas de ensino fundamental. Cada artista elaborou um projeto que foi desenvolvido em colaboração com as professoras regentes e foi acompanhado por uma pesquisadora externa que observou todo o processo e realizou uma avaliação de todo o trabalho que foi apresentada em um seminário final aberto ao público. O projeto, bem como a avaliação, está publicado no documento "Entre la escuela y el museo evaluación de 


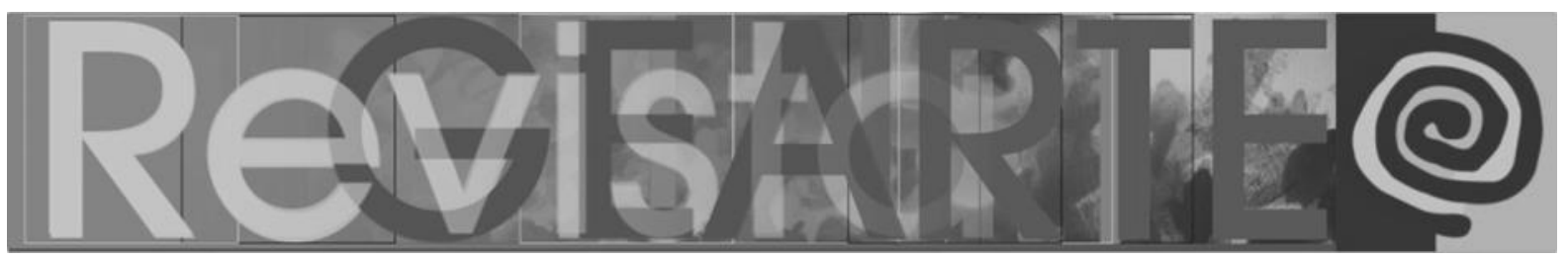

acompañamiento de residencias artísticas en colegios de primaria AQUÍ TRABAJA UN ARTISTA 2014-2015”, também disponível para download6.

Projetos como este indicam o início da abertura para um trabalho promissor no sentido de pensar que é possível inverter a ordem estabelecida na relação entre escolas e museus desde que a prática educativa nos museus teve início. E mais, é possível vislumbrar a concretização de práticas que incluam a infância, nessas ações. É o que podemos perceber na experiência, que ocorre desde o ano de 2004, entre o Centro de Arte Contemporânea "La Panera" e escolas de educação infantil da cidade de Leida, na Espanha.

Ayuso (2011) explica que o projeto “Los más pequeños visitan la Panera!”, surgiu do interesse das escolas infantis em conhecerem a instituição na época da sua abertura na cidade. Esse trabalho colaborativo entre as instituições se consolidou com a criação de uma comissão denominada Comisión Panera como "una estrategia para realizar una formación continuada con los profisionales educativos" (AYUSO, 2011, p.220). A comissão que é formada por professoras da infância e pela responsável pela educação do Centro de Arte se reúne uma vez ao mês para pensar em estratégias de trabalho, a partir das exposições presentes na instituição. As professoras selecionam conceitos que serão incorporados no projeto das escolas antes da realização de visitas com as crianças. De acordo com Ayuso, o ponto de partida "es la exposición como herramienta de conocimiento" (AYUSO, 2011, p.221). Assim, ao trabalhar com a arte contemporânea no contexto educativo se possibilita o desenvolvimento das capacidades e potencialidades das crianças pequenas e das professoras que nas sessões formativas com a Comisión Panera:

Sesión, tras sesión ampliamos la sesión de los conceptos con otros artistas contemporáneos y sus procesos creativos, de esta manera nos nutrimos [...] para ampliar neutros conocimientos en él ámbito artístico y potencializar nuestra creatividad y la de los niños. [...]. Este trabajo formativo [...] culmina en una propuesta de producción creativa que recoge a los conceptos artísticos, aunque este retorno a la exposición es totalmente abierto, flexible

6 Documento disponível em: <http://www.ca2m.org/es/primaria/aqui-trabaja-un-artista-publicacion>.

GABRE, Solange. Formação colaborativa: uma possibilidade de habitar o Museu de Arte com a Pequena Infância. 523 Revista GEARTE, Porto Alegre, v. 6, n. 3, p. 514-527, set./dez. 2019.

Disponível em: http://seer.ufrgs.br/gearte 


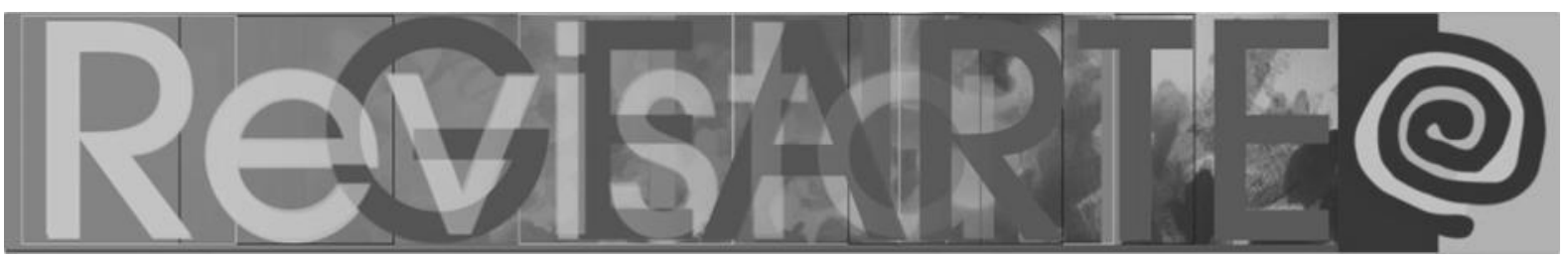

y con posibilidad de adaptarlo a los diferentes proyectos de escuela. (AYUSO, 2011, p. 222-224).

A visita ao Centro La Panera é sempre realizada na interação entre crianças, professoras e mediadores, pois para que esse momento seja uma experiência significativa, nas palavras de Ayuso (2011, p. 221) é necessário 'intervenciones conjuntas entre maestras y educadoras de La Panera para que el niño tenga la referencia de una persona adulta conocida".

Para dar visibilidade ao trabalho desenvolvido no Centro La Panera, é realizado a cada ano um evento denominado "Jornadas de Puertas Abiertas", com o objetivo de mostrar à comunidade toda a produção realizada no decorrer do ano também:

Así hacer visible a toda la ciudad la tarea educativa de los diferentes centros de enseñanza y personal docente, es un acto de reconocimiento y evaluativo para el profesorado y los alumnos, los educadores de la Panera en tanto que es un recurso público de la comunidad" (AYUSO, 2011, p. 225).

Ayuso, que é a responsável pela educação do Centro La Panera, entende que esse projeto "es un espacio de formación, donde todas aprendemos las unas de las otras". (AYUSO, 2011, p. 226).

Este projeto elucida que o envolvimento de diferentes instituições e a união de interesses em comum por meio de um trabalho colaborativo pode oportunizar a formação cultural de crianças e profissionais, a qual se reflete na formação cultural da sociedade.

Os projetos mencionados fortalecem a possibilidade de unir escolas e museus num trabalho promissor, pois a realidade atual indica que:

O cruzamento entre escolas e museus ou espaços culturais faz parte de uma rede de nódulos gigantescos pertencentes a uma estrutura rizomática impressionante para o qual tenderia uma sociedade que aposta na cultura global e local através de espaços culturais onde se desenvolvem projetos colaborativos desenhados em conjunto desde a raiz entre todos os participantes dessa interface [...] (EÇA, 2010, p. 281). 


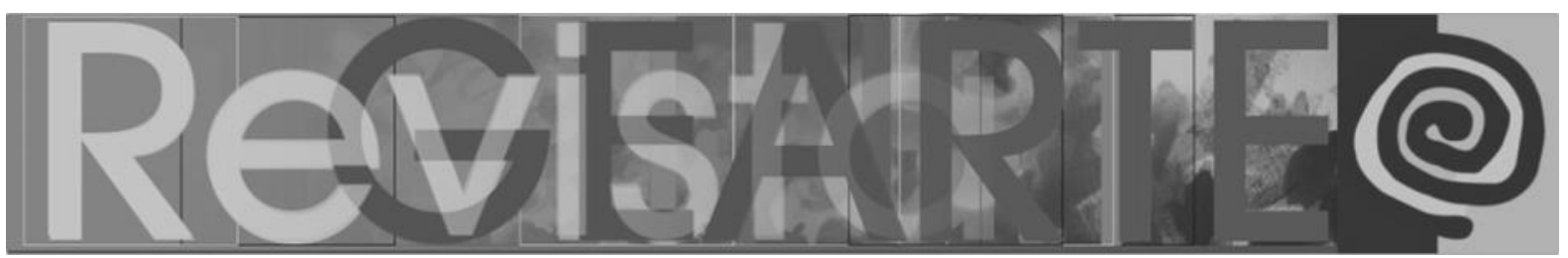

Esse pensamento sobre o desenvolvimento de formações e projetos colaborativos desde a raiz faz com que a própria instituição reveja seu papel educativo e se movimente para que mudanças aconteçam.

Ao concluir essas reflexões considera-se que as questões levantadas são basilares para (re) pensar os modelos formativos, no que se refere à formação cultural para a presença de qualidade da criança pequena no museu e Arte. Entendendo que "museus são, sobretudo, espaços de significação, lugares de experiência formativa que transita na interface da cognição com o sensível. Nesse sentido, o museu pode ser entendido como lócus, também, de marcação de uma identidade docente". (LEITE, 2012, p. 348). Portanto, é fundamental buscar caminhos possíveis para uma formação continuada conectada aos contextos e necessidades das instituições e pessoas envolvidas, apostando num trabalho que se abre para uma cultura colaborativa entre escola da infância e museu de artes.

\section{Referências}

AGUIRRE, Imanol Arriaga. El papel de la educación en el acceso democrático a la cultura y las artes. Encuentros y desencuentros entre escuela y museo. Pensamiento, palabra y obra. n. 10, p. 6-21, jul.dec., 2013. Disponível em: < http://revistas.pedagogica.edu.co/index.php/revistafba/article/view/2120> ARSLAN, Luciana Mourão; IAVELBERG, Rosa. Ensino da Arte. São Paulo: Tompson, 2006.

AYUSO, Helena. Arte contemporáneo una experiencia educativa en las escuelas de 0 a 3 años y el centro de arte. Indivisa. Boletin de Estudios e Investigación, n. 12, 2011, pp. 219-227 La Salle Centro Universitario Madrid, España.

COCA, Jiménez. Pablo. El comisariado educativo como modelo de gestión de espacios expositivos en museos de arte contemporáneo. Valladolid: Universidad de Valladolid, 2014. 72 f. Tesis Doctoral. Facultad de Educación y Trabajo Social. Departamento de Didáctica de La Expresión Musical, Plástica y Corporal. Universidad de Vallladolid, 2014.

CONSELHO NACIONAL DE EDUCAÇÃO. Conselho Pleno. Resolução CNE/CP n. 1/2006, de 15 de maio de 2006. Institui Diretrizes Curriculares Nacionais para o Curso de Graduação em Pedagogia, licenciaturas. Brasília, 2006.

DAY, Chistopher. Formar Docentes: como, cuándo y em qué condiciones aprende el professorado. Madrid: Narcea, 2005.

EÇA, Teresa, Torres. O Museu como Interface entre Cultura Local e Cultura Global. Actas do Primeiro Seminário de Investigação em Museologia dos Países de Língua Portuguesa e Espanhola, v.2, pp 274282, 2009.

GABRE, Solange de Fátima. Para habitar o museu com o público infantil: uma proposta de formação colaborativa entre professoras da infância e profissionais do Museu Municipal de Arte de Curitiba. Porto Alegre: FACED/UFRGS, 2016. (Tese de Doutorado). Programa de Pós-Graduação em Educação, Faculdade de Educação, Universidade Federal do Rio Grande do Sul, Porto Alegre, 2016. 


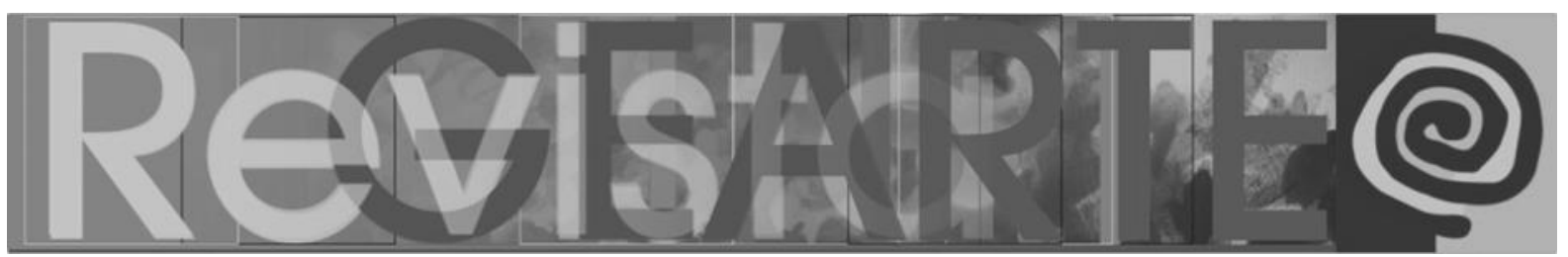

GATTI, Bernadete Angelina; BARRETTO, Elba Siqueira de Sá. Professores do Brasil: impasses e desafios. Brasília: UNESCO, 2009.

HUERTA, Ricard. ¿Por qué se Necesitan las Escuelas y los Museos? In: Maestros y Museos: educar desde la invisibilidade. Valencia: Universitat de Valencia, 2010.

IMBERNÓN, Francisco. Formação docente e profissional: formar-se para a mudança e a incerteza. $6^{a}$ edição. São Paulo: Cortez, 2006.

IMBERNÓN, Francisco. Formação permanente do professorado: novas tendências. São Paulo: Cortez, 2009.

IMBERNÓN, Francisco. Formação continuada de professores. Porto Alegre: Artmed, 2010.

KRAMER, Sônia. Produção Cultural e Educação: algumas reflexões críticas sobre educar com museus. In: KRAMER, Sônia; LEITE, Maria I. (Orgs.) Infância e Produção Cultural. Campinas, SP: Papírus, 1998.

KRAMER, Sônia. Infância, cultura contemporânea e educação contra a barbárie. Anais do Seminário Internacional da OMEP. Infância e educação infantil: reflexões para o início do século. Rio de Janeiro: Ravil, jul. 2000. pp.34-53.

KRAMER, Sônia. (Org). Profissionais da Educação Infantil: gestão e formação. São Paulo: Ática, 2008.

LEITE, Maria Isabel. Museus de Arte: espaços de educação e cultura. In: LEITE, M. I e OSTETTO, L. E. (Orgs.) Museu, Educação e Cultura: encontro de crianças e professores com a arte. Campinas, SP: Papirus, 2005.

LEITE, Maria Isabel. Experiência Estética e Formação Cultural: rediscutindo o papel da cidade e de seus equipamentos culturais. In: MAKOWIECKY, Sandra; OLIVEIRA, Sandra R. (Orgs.) Ensaios em Torno da Arte. Chapecó: Argos, 2008.

LEITE, Maria Isabel. Museu: espaço impulsionador de reconfigurações indenitárias docentes. Caderno Cedes, Campinas, v. 32, n. 88, p. 335-350, set.-dez. 2012. Disponível em: $<$ http://www.cedes.unicamp.br>

LOPES, Maria. M. A Favor da Desescolarização dos Museus. Educação e Sociedade, n. 40, dezembro, 1991.

MARTINS, Mirian Celeste. Aprendizes da arte, mediadores e professores - olhares compartilhados? In: SANTOS, Anderson Pinheiro (Org.). Diálogos entre Arte e Público: caderno de textos. Recife: Fundação de Cultura Cidade do Recife, v.3, 2010. 136p.:il.

MARTINS, Mirian C; LOMBARDI, Lucia. M. S. dos S. Arte na Pedagogia e a Formação do professor para Educação Infantil e Anos Iniciais: inquietações e esperanças. Trama Interdisciplinar, São Paulo, v. 6, n. 2, p. 23-36, maio/ago. 2015.

MARTINS, Luciana Conrado (Org.); NAVAS, Ana. Maria.; CONTIER, Djana.; SOUZA, Maria Paula Correia de. Que Público é Esse? Formação de públicos de museus e centros culturais. São Paulo: Percebe, 2013.

MÖRSCH, Carmen. Contradecirse una Misma: la educación en museos y exposiciones como práctica crítica. In: CEVALLOS, Alejandro; MACAROFF, Anahi (Orgs.). Contradecirse una Misma: museos y mediación educativa crítica. Quito: Fundación Museos de la Ciudad, 2015.

NOGUEIRA, Monique Andries. A formação cultural de professores ou a arte da fuga. Tese (Doutorado em Educação). São Paulo: Universidade de São Paulo, 2002.

NOGUEIRA, Monique. Andries. Formação cultural de professores ou a arte da fuga. Goiânia: UFG, 2008.

NÓVOA, Antonio. Formação de professores e o trabalho pedagógico. Lisboa: Educa, 2002.

NÓVOA, Antonio. Professores: Imagens do futuro presente. Lisboa: Educa, 2009.

GABRE, Solange. Formação colaborativa: uma possibilidade de habitar o Museu de Arte com a Pequena Infância. 


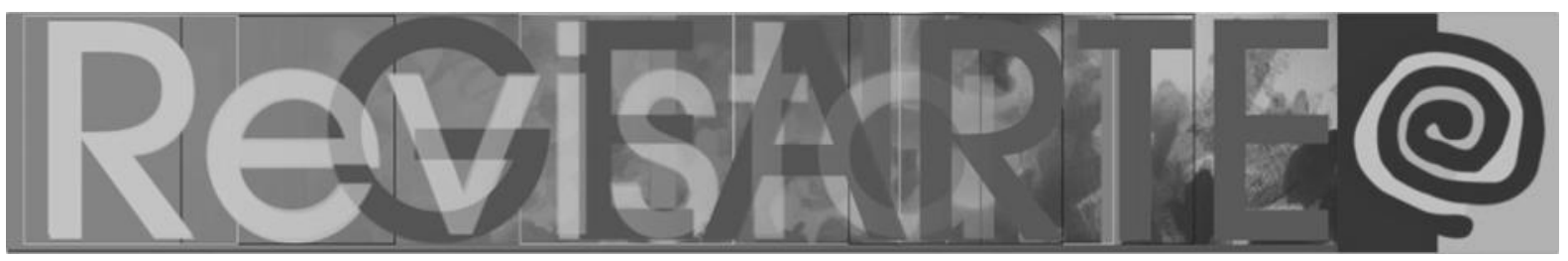

RODRIGO, Javier. Pedagogía Crítica y educación en museos. Marcos para una educación artística desde las comunidades. In: FERNÁNDEZ, O y DEL RÍO, V. (Eds.) Estrategias críticas para una práctica educativa en el arte contemporáneo. Valladolid: Museo Patio Herreriano, 2007. p. 118-132.

ROLDÃO, Maria do Céu Neves. Colaborar é preciso - Questões de qualidade e eficácia no trabalho dos professores. NOESIS. Revista Trimestral no 71 out/dez. Dossier Trabalho Colaborativo de professores. Lisboa, 2007.

SANTOS, Magaly de Oliveira Cabral. Lições das Coisas (ou Canteiro de obras) - através de uma metodologia baseada na educação patrimonial. (Dissertação de Mestrado). Rio de Janeiro: DE - PUC, 1997.

SILVA, Silvia Maria Cintra; ALMEIDA, Célia. Maria de Castro; FERREIRA, Sueli. Apropriação cultural e mediação pedagógica: contribuições de Vigotski na discussão do tema. Psicologia em Estudo, Maringá, v. 16, n. 2, p. 219-228, abr./jun. 2011.

\section{Solange Gabre}

Professora de Arte na Secretaria Municipal da Educação de Curitiba/PR. Possui graduação em Artes Plásticas pela FAP. Especialização em Museologia pela EMBAP e Educação Especial/Inclusão pela UFPR. Mestre em Patrimônio Cultural e Sociedade pela Universidade da Região de Joinville (UNIVELLE). Realizou doutorado em Educação na linha de pesquisa Arte, Linguagem e Currículo, na Universidade Federal do Rio Grande do Sul (UFRGS) com estágio na Universidad Complutense de Madrid, Espanha, pelo Programa de Doutorado Sanduíche no Exterior através da CAPES. Atua na formação de professores e mediadores culturais. Autora de artigos e capítulos de livros na área do Ensino das Artes Visuais.

ORCID: https://orcid.org/0000-0001-8903-8117

E-mail: sogabre@gmail.com

Currículo Lattes: http://lattes.cnpq.br/9774512663539144

Recebido em 29 de abril de 2019 Aceito em 24 de setembro de 2019 